Research Article

\title{
Pore Damage Properties and Permeability Change of Coal Caused by Freeze-Thaw Action of Liquid Nitrogen
}

\author{
Bo Li $\mathbb{D}^{1,2,3,4}$ Lulu Zhang $\mathbb{D}^{1}{ }^{1}$ Jianping Wei $\mathbb{D}^{1,2,3}$ and Yongjie Ren ${ }^{1}$ \\ ${ }^{1}$ School of Safety Science and Engineering, Henan Polytechnic University, Jiaozuo 454003, China \\ ${ }^{2}$ State and Local Joint Engineering Laboratory for Gas Drainage \& Ground Control of Deep Mines, Henan Polytechnic University, \\ Jiaozuo 454003, China \\ ${ }^{3}$ Collaborative Innovation Center of Coal Work Safety, Henan Polytechnic University, Jiaozuo 454003, Henan Province, China \\ ${ }^{4}$ Hebei State Key Laboratory of Mine Disaster Prevention, North China Institute of Science and Technology, Beijing 101601, China
}

Correspondence should be addressed to Bo Li; anquanlibo@163.com

Received 3 July 2018; Accepted 4 September 2018; Published 2 October 2018

Academic Editor: Ghassan Chehab

Copyright (C) 2018 Bo Li et al. This is an open access article distributed under the Creative Commons Attribution License, which permits unrestricted use, distribution, and reproduction in any medium, provided the original work is properly cited.

\begin{abstract}
A laboratory test was conducted to investigate the effect of the freeze-thaw action of liquid nitrogen on the pore structure and permeability of coal rock. First, coal rock samples with similar sound velocities and permeabilities were selected. These samples were prepared in different water saturation levels and subjected to nuclear magnetic resonance (NMR) test before and after the freeze-thaw action. Furthermore, the freeze-thaw cycle of liquid nitrogen, freezing time, and water saturation of coal rocks were controlled in permeability test. Results showed that the pore diameter, porosity, and permeability of the coal rocks increase after the freeze-thaw action of liquid nitrogen. These characteristics increase further with the increase of water saturation. The fracturing mechanisms of the freeze-thaw action of liquid nitrogen were summarized in two aspects, phase change of pore water and cold shock, and cold shock was mainly discussed. The results indicate that the effect of cold shock is still crucial at low water saturation, but it is limited by the degree of temperature drop. In general, freeze-thaw action of liquid nitrogen can cause damage to pore structure, promote the formation of fracture networks, and consequently improve the permeability of coal rock.
\end{abstract}

\section{Introduction}

Many gas reservoirs achieve low natural production because of low permeability. Hydraulic fracturing is widely used in permeability enhancement of gas reservoir because of its high efficiency, but its application has become problematic because of the shortage of water resources and the underground water pollution caused by fracturing fluid additives [1].

Earlier research has attributed the growth of pores in materials, such as rock and concrete to freeze-thaw action of liquid nitrogen [2], which can promote the growth of rock pores and provide a new method for increasing the permeability of a gas reservoir. Liquid nitrogen is used as fracturing fluid to increase gas and oil production toward the end of the last century $[3,4]$; this application is an effective means of increasing production with zero air and underground water pollution. Several researchers have explored the possibility of stimulating reservoir fracturing with liquid nitrogen jet [5]. In general, these methods aim to increase pore connectivity and permeability. Thus, the research on pore damage properties and permeability changes caused by the freeze-thaw action of liquid nitrogen is essential.

Changes in the petrophysical properties of rocks after artificial freeze-thaw action have extensively been discussed in coal region science [6]; in this field, most researchers focus on the effect of pore water on the microstructure and physical properties of rocks; when the temperature around rocks rapidly declines, the pore water inside the rocks freezes, and their volume expands by approximately $9.05 \%$; the expansion of pore water exerts a compressive stress on the pore walls, thereby resulting in rock damage [7]. Lim and $\mathrm{Ma}$ [8] conducted density and 
sound velocity tests on marbles of various water saturation levels before and after liquid nitrogen freezing and found that marbles with high water saturation show a large drop in density and sound velocity. Chen et al. [9] performed similar studies but adopted dense intervals of water saturation; thus, these researchers proposed critical water saturation, denoting that the deterioration of welded tuff can be clearly observed when the critical water saturation is surpassed. In the work of Cai et al. [10, 11], nuclear magnetic resonance (NMR) test was used to study the changes in the pore structure of dry sandstone, marble, and shale before and after liquid nitrogen freezethaw; permeability change of dry coal rock was also mentioned. Qin et al. [12] studied the changes in the petrophysical properties of coal by NMR under the freezethaw action of liquid nitrogen.

The aforementioned studies are reviewed to establish the current work, but they failed to uncover the pore damage and permeability evolution properties of coal rock with different water saturation levels caused by the freezethaw action of liquid nitrogen. Cold shock by liquid nitrogen freezing can damage coal rocks despite excluding the role of pore water in freezing $[10,13]$; this effect is disregarded in the studies on hydrous coal rocks. Therefore, in the current work, we focus on pore damage and permeability changes of both hydrous and dry coal rocks. Initially, the NMR parameters and permeability of coal rock samples were tested. Then, these samples were prepared in different water saturation levels and subjected to the freeze-thaw action of liquid nitrogen. The NMR and permeability tests of these samples were repeated. Finally, the mechanism of the freeze-thaw action of liquid nitrogen and the temperature drop of coal rocks during freezing were discussed.

\section{Experimental Method}

2.1. Sample Preparation. The raw coal samples used in the experiments were obtained from the Yima Group, Henan Province. The basic components were tested in the laboratory (Table. 1). The samples were cut from the same coal block and assembled into cylinders, each with a diameter and height of 50 and $50 \mathrm{~mm}$, respectively. The samples were dried in a dry box at $60^{\circ} \mathrm{C}$ until the sample weight is unchanged after preparing the samples, which were then subjected to sound velocity and initial permeability tests. The samples with similar velocities and initial permeabilities were selected for further testing to ensure that they are parallel. The velocities and initial permeabilities of the samples used in this work are listed in Table 2.

Coal samples with different water saturation levels are required in the tests. The degree of water saturation is different from that of water content, and water saturation is defined by the ratio of current moisture content to maximum moisture content. The preparation process of coal samples with different water saturation levels is as follows: (a) A predetermined water saturation level is set, marked as $P, \%$

(b) The selected samples are saturated with water and then weighed; the saturated weight is marked as $m_{\mathrm{s}}$

(c) The samples are dried at $60^{\circ} \mathrm{C}$ and then weighed every $30 \mathrm{~min}$ until the sample weight is near the predetermined weight denoted as $m$

The predetermined weight is calculated by using

$$
m=m_{\mathrm{d}}+p\left(m_{\mathrm{s}}-m_{\mathrm{d}}\right),
$$

where $m$ is the predetermined weight, $m ; m_{\mathrm{d}}$ is the dry weight, $m ; p$ is the predetermined water saturation level, \%; and $m_{s}$ is the saturated weight. The water saturation levels of the coal rock samples used in the experiments are presented in Table 2, where No. 1 to 4 are used for NMR test, and the rest are used for permeability test.

2.2. NMR Test. NMR is a mature, fast, and nondestructive, high-resolution detection technology, which has been used for rock pore structure analysis for a few decades [14]; it is superior to other methods because of its largest detection range for pore diameters at approximately $0.1-100,000 \mathrm{~nm}$ [15].

The relaxation properties of water in pores are critical to the NMR test, during which a Carr-Purcell-Meiboom-Gill pulse sequence is emitted to a fully saturated rock; the intensity of the pulse sequence attenuates when crossing water in pores; a curve that reflects the relaxation properties of water in pores is obtained by fitting the attenuation constant and shows the transverse relaxation time $T_{2}$ distribution [16]. Micropores obtain a small $T_{2}$ value because the pulse sequence loses less intensity in micropores than in macropores, so, the NMR parameter $T_{2}$ is directly proportional to pore diameter [17]. However, when there are many pores with the same pore diameter, the signal intensities will add up to increase the amplitude; it indicates that the amplitudes of each peak in the $T_{2}$ distribution curve reflect the number of pores [18]. The area covered by the $T_{2}$ distribution curve in Figure 1 is the $T_{2}$ spectral area, which is the multiplication of pore number and pore diameter; therefrom, $T_{2}$ spectral area is positively correlated to porosity [18]. Figure 1 shows a $T_{2}$ distribution curve of a coal rock. In this curve, the first peak $\left(P_{1}\right)$ is much higher than the second peak $\left(P_{2}\right)$, thereby indicating that the micropores are more than the macropores in the coal rock tested.

2.3. Permeability Test. A triaxial seepage experiment system was used in the permeability test. The working principle diagram of this system is illustrated in Figure 2. During the test, $1 \mathrm{MPa}$ uniaxial pressure and $2 \mathrm{MPa}$ confining pressure were loaded on coal rock by a manual metering pump. High gas pressure (inlet pressure, $0.45 \mathrm{MPa}$ ) is loaded at one end of the sample, and atmospheric pressure (outlet pressure, $0.1 \mathrm{MPa}$ ) is loaded at the other end. The gas pressure difference between the two ends allows nitrogen to 
TABle 1: Component and basic parameters of coal rocks used in the experiments.

\begin{tabular}{|c|c|c|c|c|}
\hline Tests & & Par & ers/values & \\
\hline Proximate analysis (\%) & $\begin{array}{l}\mathrm{M}_{\mathrm{ad}} \\
3.94\end{array}$ & $\begin{array}{r}\mathrm{V}_{\mathrm{daf}} \\
16.52\end{array}$ & $\begin{array}{c}\mathrm{A}_{\mathrm{ad}} \\
12.24\end{array}$ & $\begin{array}{l}\mathrm{F}_{\mathrm{Cad}} \\
67.30\end{array}$ \\
\hline Maceral composition (vol\%) & $\begin{array}{c}\mathrm{V} \\
78.26\end{array}$ & $\begin{array}{c}\mathrm{I} \\
16.17\end{array}$ & $\begin{array}{c}\mathrm{E} \\
4.46\end{array}$ & $\begin{array}{c}\mathrm{M} \\
1.11\end{array}$ \\
\hline Elemental analysis (\%) & $\begin{array}{c}\mathrm{C}_{\mathrm{daf}} \\
68.80\end{array}$ & $\begin{array}{l}\mathrm{H}_{\mathrm{daf}} \\
5.09\end{array}$ & $\begin{array}{l}\mathrm{N}_{\mathrm{daf}} \\
1.00\end{array}$ & $\begin{array}{r}\mathrm{O}_{\mathrm{daf}} \\
25.11\end{array}$ \\
\hline Basic parameters & $\begin{array}{c}\text { Density }\left(\mathrm{g} / \mathrm{cm}^{3}\right) \\
1.48\end{array}$ & $\begin{array}{l}\text { Elastic module }(\mathrm{GPa}) \\
2.35\end{array}$ & $\begin{array}{c}\text { Compressive strength }(\mathrm{MPa}) \\
18\end{array}$ & $\begin{array}{c}\text { Poisson's ratio } \\
0.28\end{array}$ \\
\hline
\end{tabular}

Note. Proximate analysis was based on the standard of GB/T212-2008. $\mathrm{M}_{\mathrm{ad}}$, moisture, air-drying basis; $\mathrm{A}_{\mathrm{ad}}$, ash yield, air-drying basis; $\mathrm{V}_{\mathrm{daf}}$, volatility, dry ashfree basis; $\mathrm{FC}_{\mathrm{ad}}$, fixed carbon content, air-drying basis. V, vitrinite; I, inertinite; $\mathrm{E}$, exinite; $\mathrm{M}$, minerals.

TABLE 2: Initial information of coal rock samples.

\begin{tabular}{|c|c|c|c|c|c|c|c|c|c|c|c|c|c|}
\hline & 1 & 2 & 3 & 4 & 5 & 6 & 7 & 8 & 9 & 10 & 11 & 12 & 13 \\
\hline Soun & 1378 & 1467 & 1408 & 397 & 469 & 1486 & 1519 & 1397 & 1436 & 1468 & 1501 & 1430 & 1459 \\
\hline $\left.0^{-15} \mathrm{~m}^{2}\right)$ & .093 & 0.0945 & 0.0986 & 0.0943 & 0.091 & 0.1 & 0.0925 & 0.099 & 0.097 & 0.0915 & 0.0913 & 0.0921 & 0.09 \\
\hline Water saturation $(\%)$ & 0 & 34.2 & 67.8 & 92.4 & 0 & 0 & 0 & 10.9 & 31.8 & 48.2 & 68.7 & 81.4 & 100 \\
\hline
\end{tabular}

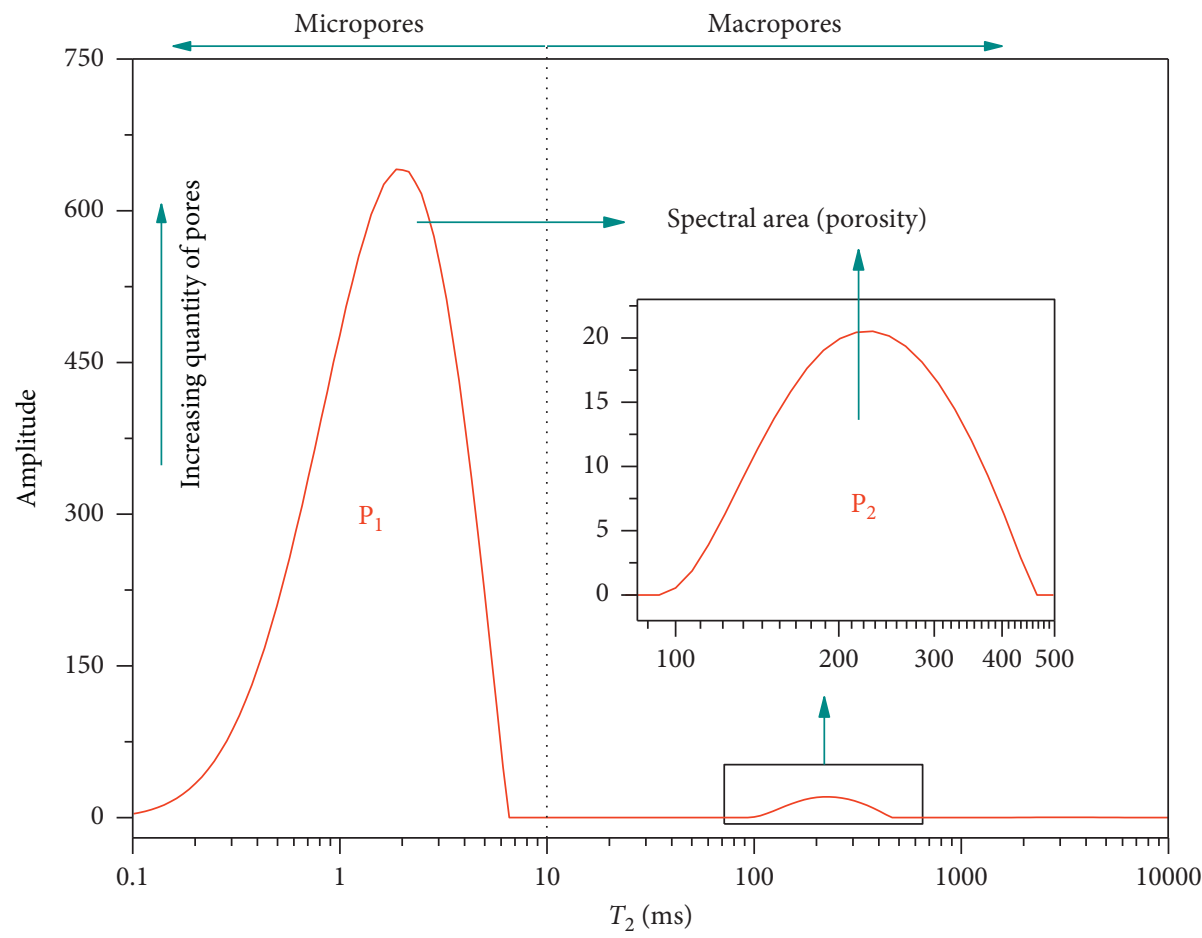

FIgURE 1: $T_{2}$ distribution curve of coal rock.

permeate through the coal rock sample. The permeated flow information is collected by a flowmeter. The permeability of the coal rock samples is calculated by using the following equation.

$$
k=\frac{0.2 p_{0} \mu L Q}{A\left(p_{1}^{2}-p_{2}^{2}\right)},
$$

where $k$ is the permeability of the sample, $10^{-15} \mathrm{~m}^{2} ; p_{0}$ is the atmospheric pressure, $0.1 \mathrm{MPa} ; \mu$ is the nitrogen dynamic viscosity, $17.805 \times 10^{-6} \mathrm{pa} \cdot \mathrm{s}$; $L$ is the sample length, $5 \mathrm{~cm}$; $Q$ is the air flow capacity, $\mathrm{cm}^{3} / \mathrm{s} ; A$ is the bottom area of the sample, $19.625 \mathrm{~cm}^{2}$; and $p_{1}$ and $p_{2}$ are the inlet and outlet pressures, respectively, 0.45 and $0.1 \mathrm{MPa}$.

\section{Results}

3.1. NMR Test Results. In the NMR test, the coal rock samples were subjected to NMR test after being saturated with water. Then, they were prepared into different water saturation levels and immersed in liquid nitrogen for $2 \mathrm{~h}$. After that the samples were resaturated with water and subjected to NMR test again. The concise experimental 


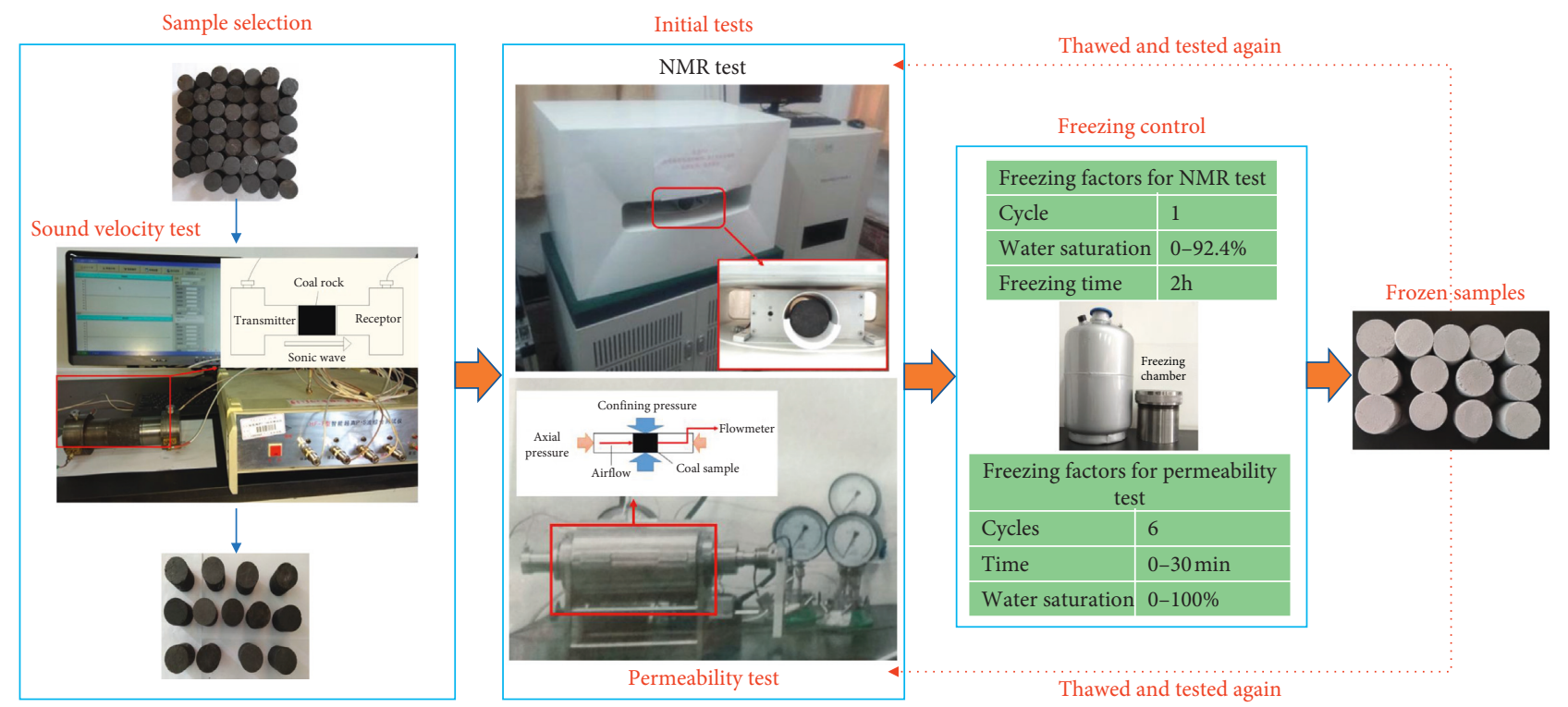

FIgURE 2: Equipment used in the experiment and concise experimental procedures.

procedures are depicted in Figure 2. The experimental results are as follows.

3.1.1. Changes in $T_{2}$ Distribution Curve. The pore damage properties were obtained by comparing the $T_{2}$ distribution curves before and after liquid nitrogen soaking. The changes of the $T_{2}$ distribution curve are presented in Figure 3, which indicates the following three properties.

(1) The $T_{2}$ distribution curve moves upward after liquid nitrogen freezing, characterized by the increase of peak amplitudes. The increase of the amplitude of each peak with water saturation is displayed in Figure 4. The increase of the amplitude is more obvious in the second peak than in the first peak. This result indicates that new pores, especially macropores, are generated after liquid nitrogen freezing.

(2) The $T_{2}$ distribution curve moves to the right after liquid nitrogen freezing, characterized by the increase of the maximum transverse relaxation time. The maximum relaxation time of the dry sample increases from $265.8 \mathrm{~ms}$ to $305.4 \mathrm{~ms}$, whereas the maximum relaxation time of the sample with a saturation of $92.4 \%$ significantly improves from $305.3 \mathrm{~ms}$ to $432.9 \mathrm{~ms}$. The results indicate an increase in pore diameter.

(3) The two results highlight the importance of water saturation. Liquid nitrogen freezing causes more damage to hydrous than to dry coal rock.

3.1.2. Changes in $T_{2}$ Spectral Area. The changes of spectral areas are illustrated in Figure 4. The $T_{2}$ spectral areas increase after the freeze-thaw action, especially for the second peak and hydrous coal rock. This result indicates that the porosity of the coal rock grows after liquid nitrogen freezing, and macropores exhibit a significant growth. The water in pores plays an important role in pore volume growth under liquid nitrogen freezing.

After the freeze-thaw action of liquid nitrogen, the porosity and pore diameter of coal rock increase, and new pores are produced. The growth of new pores and the porosity of macropores are exponentially related to water saturation, whereas linear fit is used for the growth of micropores. The fitting curve depicts that the increase in the number and volume of micropores at a water saturation of $92.4 \%$ is much lower than the fitting curve. This result indicates that certain micropores are connected to macropores, thereby leading to a significant increase in the number of macropores and a minimal increase in the number of micropores.

3.2. Permeability Test Results. Permeability is an important parameter for measuring reservoir yield and is highly related to pore diameter and porosity. Permeability is defined in Equation (3) on the basis of Darcy's law [19].

$$
k=\frac{r^{2} \varphi}{8}
$$

where $r$ is the capillary radius and $\varphi$ is the porosity. Thus, the permeability of coal rock can be increased by liquid nitrogen freeze-thaw action because the enhancement of pore diameter and porosity occurs after liquid nitrogen freezing. In the permeability test, three factors, namely, freezing cycle, freezing time, and water saturation of coal rock, were controlled (Figure 2). In controlling freezing cycle, the dry coal rock sample was immersed in liquid nitrogen for $5 \mathrm{~min}$ each cycle. At the intervals of each cycle, the sample was recovered to room temperature in an airtight bag and subjected to another permeability test. In controlling freezing time, the dry coal rock was frozen in liquid nitrogen for $5 \mathrm{~min}$ in the first cycle and then frozen 


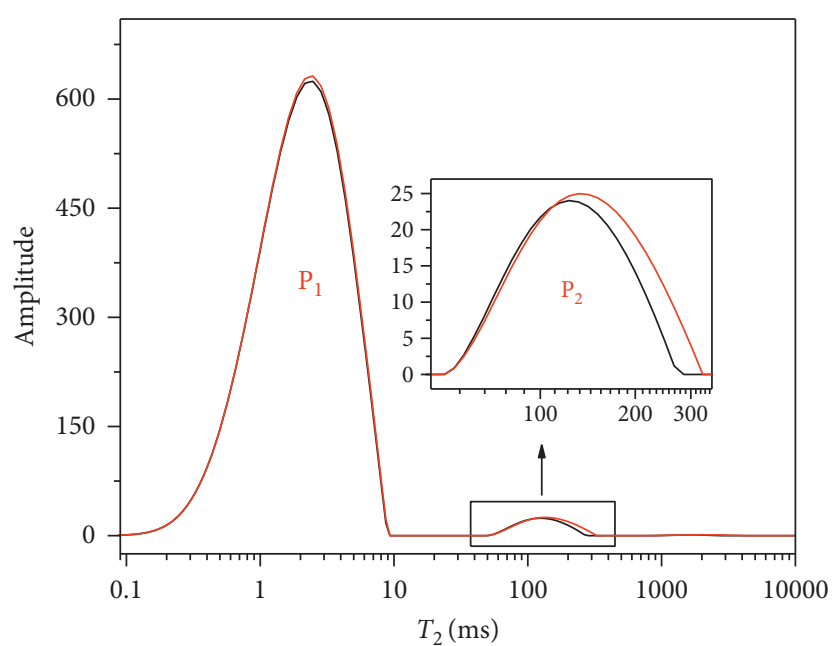

- Before

- After

(a)

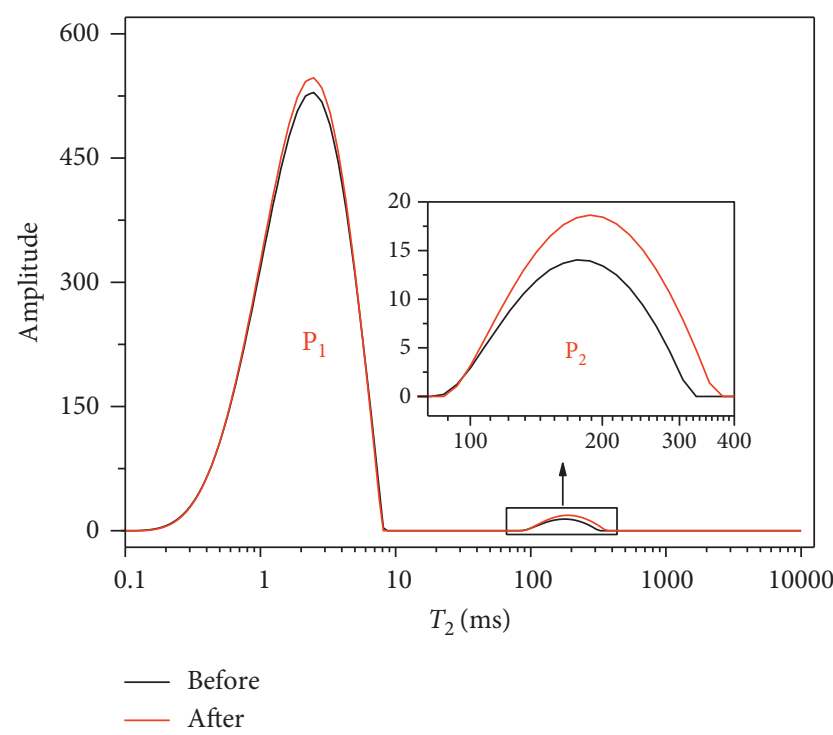

(c)

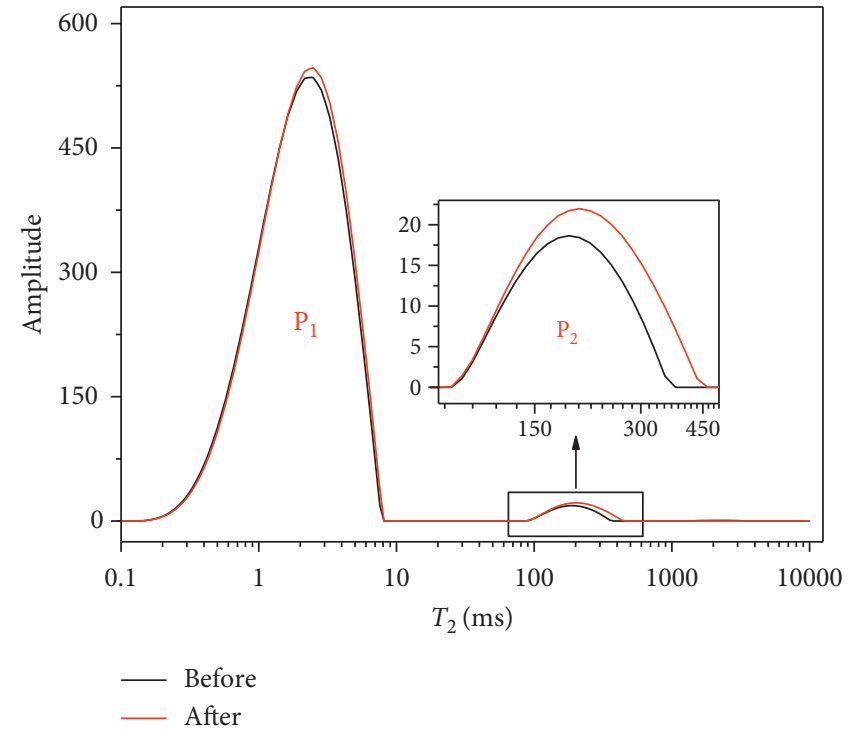

(b)

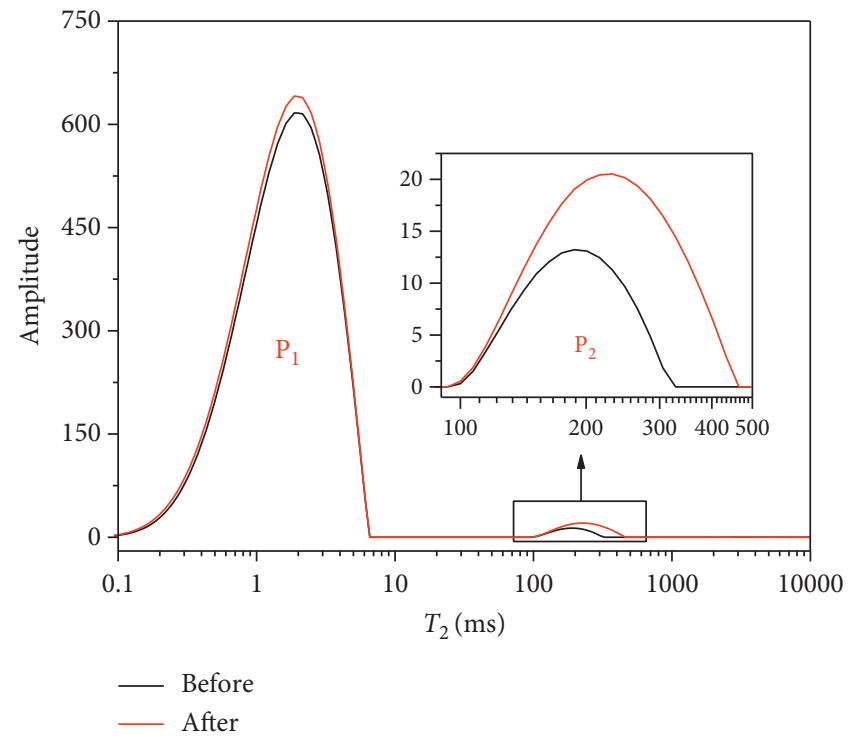

(d)

Figure 3: Contrast of $T_{2}$ distribution curve before and after the freeze-thaw action of liquid nitrogen. (a) Water saturation $0 \%$. (b) Water saturation $34.2 \%$. (c) Water saturation $67.8 \%$. (d) Water saturation $92.4 \%$.

for 5 min more than the last cycle in the next few cycles. In controlling water saturation, the coal rocks of different water saturation levels were frozen in liquid nitrogen for $2 \mathrm{~h}$ and recovered to room temperature, dried, and subjected to another permeability test. The experimental results are discussed below.

3.2.1. Freeze-Thaw Cycle and Freezing Time. The effects of the freeze-thaw cycle and freezing time on permeability are illustrated in Figure 5. The permeability of dry coal rock sample improves by $34.98 \%$ after six cycles of freeze-thaw action. However, the permeability of the sample increases significantly after the first cycle and barely shows any change in the next five cycles. The freeze-thaw cycles in the experiment can be considered cyclic loads. The last five cyclic loads are below the determined strength of coal rock; nevertheless, cyclic loads may cause minimal damage due to the effect of fatigue failure [20]. However, fatigue damage caused by several freeze-thaw cycles is so minimal that it cannot be detected in the experiment. Thus, the permeability change rule under freeze-thaw cyclic conditions is valid only in several cycles because fatigue damage should be considered if the number of freeze-thaw cycles is high [21].

The permeability of the coal samples continuously increases when the freezing time is extended in the next cycle but stabilizes afterward. Thus, the permeability of coal rock can be enhanced by increasing the freezing time over a period of time, but must not as long as possible, because the 


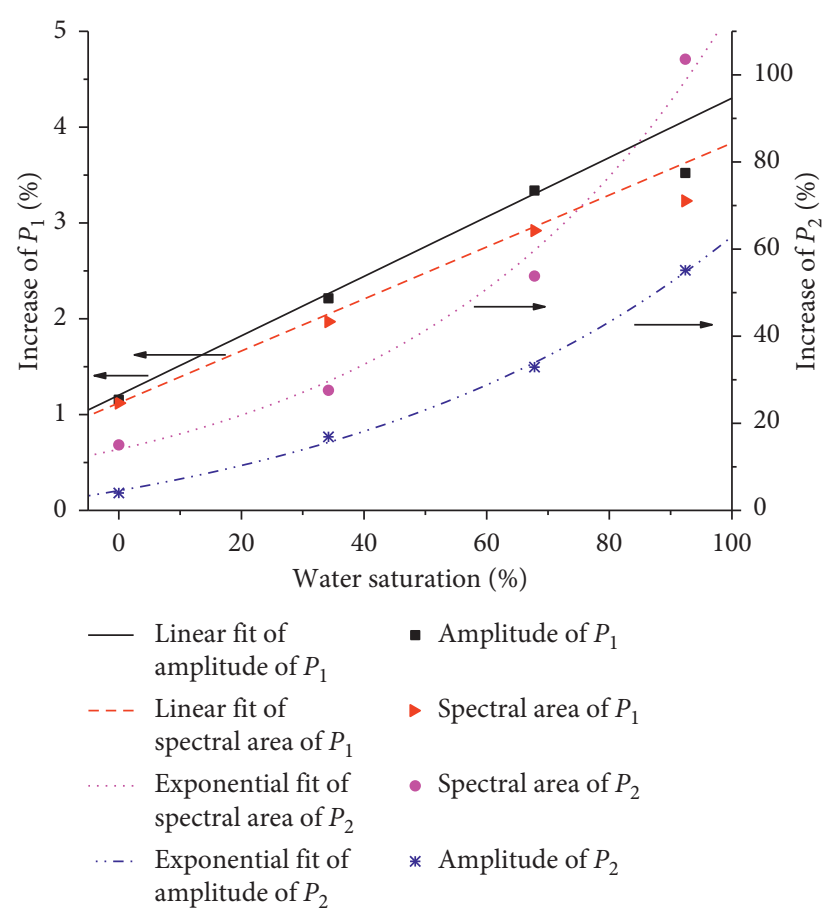

FIgURE 4: Increases in amplitude and spectral area with water saturation.

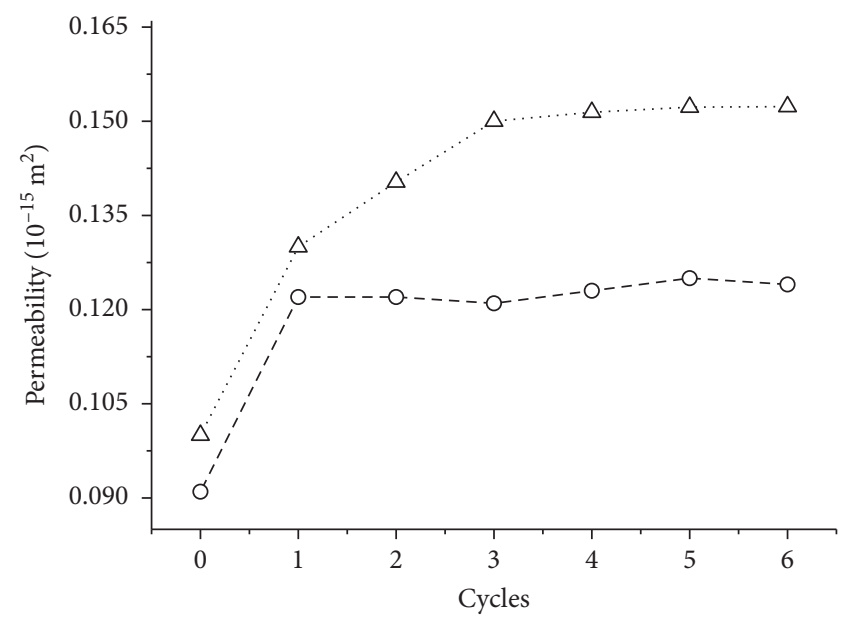

$\triangle$. 5 minutes more than last cycle

- O- 5 minutes for each cycle

FIGURE 5: Changes in permeability with freeze-thaw cycles of liquid nitrogen.

permeability of coal rock sample is unchanged when the freezing time exceeds $20 \mathrm{~min}$. Overall, the permeability of the dry coal rock increases by $52.34 \%$.

3.2.2. Water Saturation. Figure 6 illustrates that the permeability of the dry sample increases by approximately $49.18 \%$ after freeze-thaw cycle, but the increase is insignificant relative to the hydrous samples. The permeability increases by $66.80 \%, 130.33 \%, 207.48 \%, 322.52 \%, 533.40 \%$,

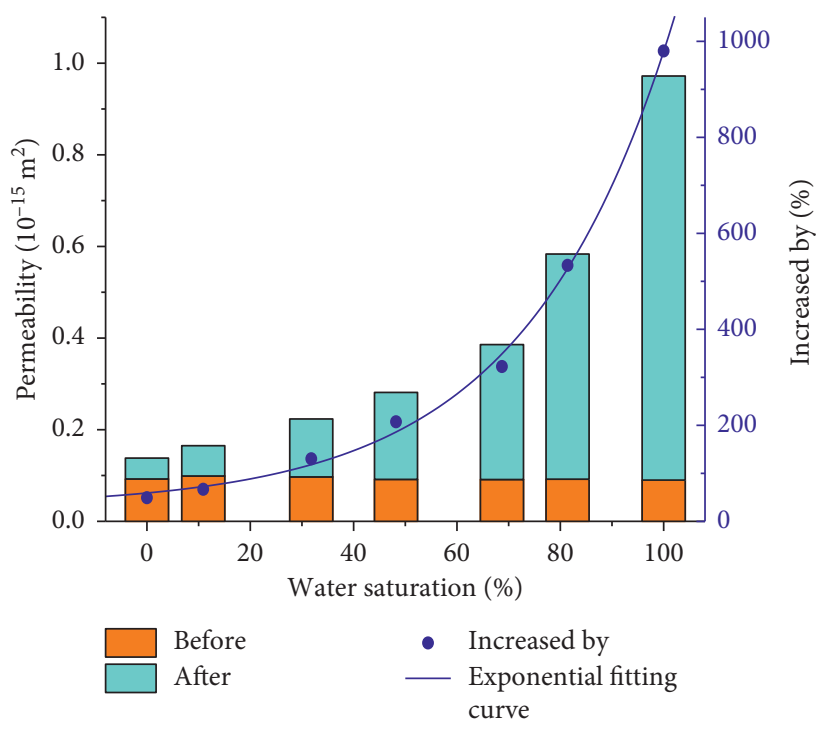

FIgURE 6: Changes in permeability with water saturation.

and $980 \%$ when the water saturation levels of the coal rocks are $10.9 \%, 31.8 \%, 48.2 \%, 68.7 \%, 81.4 \%$, and $100 \%$, respectively, thereby presenting an exponential function with water saturation. These results imply that permeability has a slow growth rate under low water saturation and a rapid growth rate under high water saturation, thus indicating critical water saturation. The critical water saturation is about $70 \%$. The critical water saturation is also observed in the increase of amplitude and spectral area of $P_{2}$ with water saturation (Figure 4).

\section{Discussion}

4.1. Negative Damage. Several researchers compared the $T_{2}$ distribution curves of dried sandstone before and after liquid nitrogen freeze-thaw and found that the $T_{2}$ distribution curve shifts downward and leftward, indicating a decrease in the porosity and pore diameter of sandstone; certain researchers refer to this decreasing phenomenon as negative damage $[10,22]$. In the current work, the experimental data denotes that negative damage does not exist in a dried coal rock (Figures 3, 5, and 6). Therefore, coal rock has different pore damage properties with sandstone after liquid nitrogen freeze-thaw. The pore structure of coarse-grained rock types with high heterogeneity is likely to become damaged when these rocks are subjected to cold shock, whereas fine-grained rock types with low heterogeneity are prone to crack healing [13]. Therefore, sandstone is prone to negative damage, whereas coal rock, which is a porous medium with mixed components and colloid particles (Table 1), is likely to show the growth of pores.

4.2. Fracturing Mechanism of the Freeze-Thaw Action of Liquid Nitrogen. The experimental results indicate that water in coal rock plays an important role in the freeze-thaw action of liquid nitrogen. During freezing, pore water causes damage to the coal rock in three techniques [23], namely, 
frost-heaving force, formation of ice lens or wedge, and hydraulic pressure. Frost-heaving force is the main factor [24]. The water in a coal rock becomes ice during freezing, thereby resulting in volume expansion, which causes the squeezing of pore walls. Several studies have shown that frost-heaving force caused by pore water phase change is more than $60 \mathrm{MPa}[2,25]$, which is greater than the compressive strength of coal rock and apparently sufficiently large to disrupt pore structure and coal matrix, thus leading to the expansion and the generation of pores. The volume of water after phase transition increases by approximately $9.05 \%$. For the coal rock with low water saturation, the water saturation of most pores is lower than $90.95 \%$, so, the volume expansion of water caused by phase transition is insufficient in filling the entire pore space and fails to generate frost-heaving force. At a high water saturation level, frost-heaving force exists in most pores, and the migration of pore water causes the water saturation of numerous pores to exceed $90.95 \%$ [9]. Consequently, critical water saturation exists.

In addition to the effect of water in hydrous coal rocks, the damage of dry coal rock was observed in the NMR and permeability tests with the upward movement of the $T_{2}$ distribution curve and the increase of permeability. This result predicts the role of cold shock during freezing. The temperature of the surface drops when coal rock is rapidly cooled, while the internal temperature remains unchanged due to poor heat transfer. The surface contraction is limited by the internal matrix, thereby leading to tensile stress on the surface [26]; the concentration of tensile stress on the tip of the pore causes the expansion of pore diameter [27]. In addition, colloid particles demonstrate different cold contractions with the coal rock matrix, and the differences in contraction can disrupt the colloid structure by generating new micropores [22]. Therefore, the increase of porosity and pore diameter were detected in the NMR test (Figures 3 and 4).

Many researchers highlight the importance of pore water during freeze-thaw action $[9,12]$. The damage of dry coal rock is caused by cold shock, whereas the damage of hydrous coal rock is the joint effect of pore water and cold shock. However, Figure 6 illustrates that cold shock plays an important role in the low water saturation phase.

4.3. Temperature Drop of Coal Rock. Temperature drop is a physical parameter that measures the range of temperature change. Previous studies have shown a correlation between temperature drop and pore damage [27]. The temperature drop of coal rock was indirectly tested in the experiments in the current work, but temperature drop was closely related to freezing time [28]. An extended freezing time leads to a significant temperature drop, serious damage [27], and considerable increase of permeability (Figure 5). Thus, the temperature drops of each cycle are basically the same with the same freezing time. Temperature drop can continuously increase only when the freezing time is extended. However, the temperature of the coal rock equals the temperature of liquid nitrogen when the freezing time is sufficiently extended; this will lead to an end to the increase of the permeability of coal rock. Therefore, the cumulative freezing time is disregarded. This result can also explain the permeability change in the freeze-thaw cycle and freezing time (Figure 5). The temperature drop distribution of the coal rock when the ambient temperature changes can be expressed by the following equation [28]:

$$
\begin{aligned}
T(x, t)= & T_{0}\left[\operatorname{erf} \frac{x}{2 \sqrt{\kappa t}}+\exp \left(h x+h^{2} \kappa t\right)\right. \\
& \left.\times \operatorname{erfc}\left(\frac{x}{2 \sqrt{\kappa t}}+h \sqrt{\kappa t}\right)\right]
\end{aligned}
$$

where $T(x, t)$ is the temperature drop of coal rock, ${ }^{\circ} \mathrm{C} ; x$ is the distance between the interior and surface, $m ; t$ is the freezing time, $s ; T_{0}$ is the maximum temperature $\operatorname{drop}\left({ }^{\circ} \mathrm{C}\right)$ in this work, that is, $226^{\circ} \mathrm{C}$ (coal rock, $30^{\circ} \mathrm{C}$; liquid nitrogen, $\left.-196^{\circ} \mathrm{C}\right) ; h$ is the ratio of the surface heat transfer coefficient to thermal conductivity $\left(105.19 \mathrm{~m}^{-1}\right)$; and $\kappa$ is the thermal diffusivity $\left(4.914 \times 10^{-7} \mathrm{~m}^{2} / \mathrm{s}\right)$. The relationship between the average temperature drop $T(t)$ and freezing time $t$ is obtained by integrating $x$ in Equation (4). The relationship between the average temperature drop and freezing time of the coal rock sample with a diameter and height of 50 and $50 \mathrm{~mm}$, correspondingly, is plotted in Figure 7.

In Figure 7 , the surface temperature drop increases quickly, whereas the middle temperature drop remains 0 for the first $2 \mathrm{~min}$ and denotes a relatively slower growth than the surface temperature drop. This result indicates that the internal coal rock requires additional time to transmit heat to liquid nitrogen. Heat transfer time is determined by the size of the coal rock and its heat transfer property [29]; therefore, coal rocks with a large-size and poor heat-transfer property require additional time to reach the maximum temperature drop. Consequently, the stability time of permeability varies and depends on the size and heat-transfer property of coal rocks.

The average temperature drop of the coal and rock samples did not reach the maximum temperature drop after freezing for $30 \mathrm{~min}$, and only reached approximately $86 \%$ of the maximum temperature drop. The experimental data indicated that the permeability of the coal rock samples stabilizes even when the temperature does not reach the maximum. During freezing, liquid nitrogen may seep into a coal rock through fissures. Mass transfer allows coal rocks to easily transfer heat to liquid nitrogen [30], which is disregarded in Equation (4). Thus, permeability is stabilized ahead.

In general, the change in the average temperature drop and permeability of coal rock with freezing time indicates a similar trend. Thus, a linear relationship may exist between temperature drop and permeability. The relationship can be expressed as follows:

$$
k=a T(t)+b,
$$

where $a$ and $b$ are the fitting parameters, $T(t)$ is the average temperature drop, and $k$ is the permeability of coal rock. The 


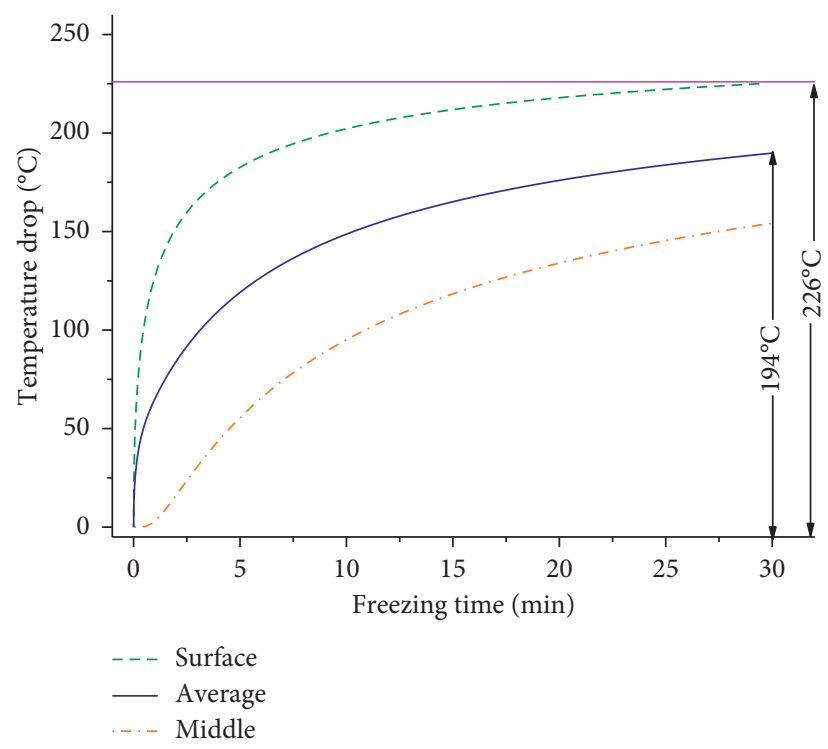

Figure 7: Temperature drop of coal rock with the size of $\varphi$ $50 \mathrm{~mm} \times h 50 \mathrm{~mm}$ during liquid nitrogen freezing.

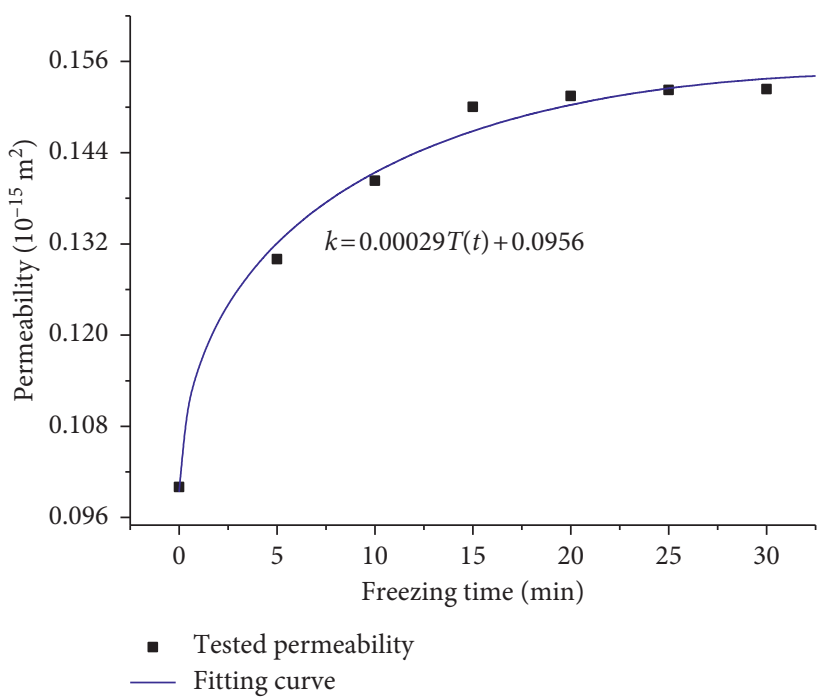

Figure 8: Linear fit of temperature drop and permeability.

equation was used to fit the experimental data in Figure 5. The result is displayed in Figure 8.

Figure 8 depicts that most data are above fitting curve due to mass transfer. However, vaporizing liquid nitrogen at the coal rock surface prevents the action of mass transfer at the beginning of freezing. In this case, mass transfer is inoperative. Evaporation is diminished with the surface temperature drop, and the action of mass transfer should be considered. Therefore, the fitting curve is consistent with the experimental data at the beginning but is lower than the tested data afterward. Nevertheless, the fitting accuracy is 0.92 . Therefore, the linear relationship between the permeability of coal rock and the average temperature is reasonable. The permeability of coal rocks can be increased by enlarging the cold shock range.

\section{Conclusions}

The pore damage properties and permeability changes of coal rocks after the freeze-thaw action of liquid nitrogen were investigated. The fracturing mechanisms of liquid nitrogen and the temperature drop of coal rocks during freezing were discussed. The major conclusions of this work are summarized as follows.

After the freeze-thaw action of liquid nitrogen, the increase in pore diameter, porosity, and permeability is observed in the experiments, these changes continue with the increase of water saturation, especially when the water saturation is higher than $70 \%$. Two aspects of the fracturing mechanism of liquid nitrogen, namely, cold shock and pore water phase change, were also studied. The thermal degradation of dried coal rocks results in cold shock, whereas the damage of hydrous coal rocks is the joint effect of the two aspects. These effects expand pores and destroy the colloid structure of coal rocks, thereby resulting in an increase in pore diameter, porosity, and permeability. Even though phase change of pore water is the main cause of pore damage, cold shock still plays an important role in the low water saturation stage.

Coal rocks hardly exhibit negative damage after cold shock because of its coarse-grained and heterogeneous structure. However, the cold shock is limited in terms of increasing permeability. The concept of temperature drop of coal rocks was proposed to clarify this limitation. Permeability growth stops when the temperature drop reaches the maximum. The evolution of temperature drop is highly related to pore diameter, heat transfer properties, and freezing time. Coal rocks with a large size and poor heat transfer properties require an extended freezing time to reach its limitation. On the basis of the temperature drop evolution model, a linear relationship was established between temperature drop and permeability and confirmed by fitting the experimental data.

\section{Data Availability}

The data used to support the findings of this study are available from the corresponding author upon request.

\section{Conflicts of Interest}

The authors declare that they have no conflicts of interest.

\section{Acknowledgments}

This research was funded by National Natural Science Foundation for Young Scientists of China (grant nos. 51604096, 51604116, 51704099, and 51574112), Hebei State Key Laboratory of Mine Disaster Prevention (grant no. KJZH2017K08), Natural Science Foundation of Hebei Province (grant no. E2016508036), Basic and Frontier Technology Research Project of Henan Province in 2016 (grant no. 162300410031), Doctoral Fund of Henan Polytechnic University (grant no. B2015-05), and Open Fund of Energy Platform Laboratory Project (grant no. G201609). 


\section{References}

[1] H. Boudet, C. Clarke, D. Bugden, E. Maibach, C. RoserRenouf, and A. Leiserowitz, "Fracking controversy and communication: using national survey data to understand public perceptions of hydraulic fracturing," Energy Policy, vol. 65 , pp. 57-67, 2014.

[2] E. M. Winkler, "Frost damage to stone and concrete: geological considerations," Engineering Geology, vol. 2, no. 5, pp. 315-323, 1968.

[3] B. W. Mcdaniel, S. Grundmann, W. Kendrick, D. Wilson, and S. Jordan, "Field applications of cryogenic nitrogen as a hydraulic fracturing fluid," Journal of Petroleum Technology, vol. 50, no. 3, pp. 38-39, 1998.

[4] S. R. Grundmann, G. D. Rodvelt, G. A. Dials, and R. E. Allen, "Cryogenic nitrogen as a hydraulic fracturing fluid in the devonian shale," in Proceedings of SPE Eastern Regional Meeting, Society of Petroleum Engineers, Pittsburgh, PA, USA, January 1998.

[5] C. Z. Cai, Z. W. Huang, G. S. Li, F. Gao, J. W. Wei, and R. Li, "Feasibility of reservoir fracturing stimulation with liquid nitrogen jet," Journal of Petroleum Science and Engineering, vol. 144, pp. 59-65, 2016.

[6] J. Park, C. U. Hyun, and H. D. Park, "Changes in microstructure and physical properties of rocks caused by artificial freeze-thaw action," Bulletin of Engineering Geology and the Environment, vol. 74, no. 2, pp. 555-565, 2015.

[7] N. Matsuoka, "Mechanisms of rock breakdown by frost action: an experimental approach," Cold Regions Science and Technology, vol. 17, no. 3, pp. 253-270, 1990.

[8] S. Y. Lim and G. W. Ma, "Dynamic properties of granite exposed to low temperature," in Proceedings of 42nd US Rock Mechanics Symposium (USRMS), American Rock Mechanics Association, San Francisco, CA, USA, June-July 2008.

[9] T. C. Chen, M. R. Yeung, and N. Mori, "Effect of water saturation on deterioration of welded tuff due to freeze-thaw action," Cold Regions Science and Technology, vol. 38, no. 2-3, pp. 127-136, 2004.

[10] C. Cai, G. Li, Z. Huang, Z. Shen, S. Tian, and J. Wei, "Experimental study of the effect of liquid nitrogen cooling on rock pore structure," Journal of Natural Gas Science and Engineering, vol. 21, pp. 507-517, 2014.

[11] C. Cai, G. Li, Z. Huang, S. Tian, Z. Shen, and X. Fu, "Experiment of coal damage due to super-cooling with liquid nitrogen," Journal of Natural Gas Science and Engineering, vol. 22, pp. 42-48, 2015.

[12] L. Qin, C. Zhai, S. Liu, J. Xu, G. Yu, and Y. Sun, "Changes in the petrophysical properties of coal subjected to liquid nitrogen freeze-thaw-a nuclear magnetic resonance investigation," Fuel, vol. 194, pp. 102-114, 2017.

[13] K. Kim, J. Kemeny, and M. Nickerson, "Effect of rapid thermal cooling on mechanical rock properties," Rock Mechanics and Rock Engineering, vol. 47, no. 6, pp. 2005-2019, 2014.

[14] A. Timur, "Pulsed nuclear magnetic resonance studies of porosity, movable fluid, and permeability of sandstones," Journal of Petroleum Technology, vol. 21, no. 6, pp. 775-786, 1969.

[15] Y. Yao, D. Liu, Y. Che, D. Tang, S. Tang, and W. Huang, "Petrophysical characterization of coals by low-field nuclear magnetic resonance (NMR)," Fuel, vol. 89, no. 7, pp. 13711380, 2010.

[16] N. G. Cutmore, B. D. Sowerby, L. J. Lynch, and D. S. Webster, "Determination of moisture in black coal using pulsed nuclear magnetic resonance spectrometry," Fuel, vol. 65, no. 1, pp. 34-39, 1986.

[17] R. L. Kleinberg, "NMR measurement of petrophysical properties," Concepts in Magnetic Resonance, vol. 13, no. 6, pp. 404-406, 2001.

[18] G. P. Frosch, J. E. Tillich, R. Haselmeier, M. Holz, and E. Althaus, "Probing the pore space of geothermal reservoir sandstones by nuclear magnetic resonance," Geothermics, vol. 29, no. 6, pp. 671-687, 2000.

[19] D. Tiab and E. C. Donaldson, “Applications of Darcy's law," in Petrophysics, Chapter 7, pp. 359-414, Gulf Professional Publishing, Boston, MA, USA, 4th edition, 2016.

[20] E. Yatsu, The Nature of Weathering: An Introduction, Sozosha, Tokyo, Japan, 1988.

[21] K. Hall and C. E. Thorn, "Thermal fatigue and thermal shock in bedrock: an attempt to unravel the geomorphic processes and products," Geomorphology, vol. 206, pp. 1-13, 2014.

[22] C. Cai, G. Li, Z. Huang, S. Tian, Z. Shen, and H. Wang, "Experimental study on effect of liquid nitrogen on rock failure during cryogenic nitrogen fracturing," Journal of China University of Petroleum, vol. 38, no. 4, pp. 507-517, 2014.

[23] M.E. Young and C. McLean, "Stone cleaning in Scotlanda literature review," in Research Commission Investigating the Effects of Cleaning Sandstone, pp. 38-39, Robert Gordon University, Aberdeen, Scotland, UK, 1992.

[24] O. Sass, "Rock moisture fluctuations during freeze-thaw cycles: preliminary results from electrical resistivity measurements," Polar Geography, vol. 28, no. 1, pp. 13-31, 2004.

[25] X. Tan, W. Chen, H. Liu, L. Wang, W. Ma, and A. H. C. Chan, "A unified model for frost heave pressure in the rock with a penny-shaped fracture during freezing," Cold Regions Science and Technology, vol. 153, pp. 1-9, 2018.

[26] K. Kim and J. Kemeny, "Effect of thermal shock and rapid unloading on mechanical rock properties," in Proceedings of 43rd US Rock Mechanics Symposium and 4th U.S.-Canada Rock Mechanices Symposium, Asheville, American Rock Mechanics Association, NC, USA, June-July 2009.

[27] D. Tran, A. Settari, and L. Nghiem, "Initiation and propagation of secondary cracks in thermo-poroelastic media," in Proceedings of 46th US Rock Mechanics/Geomechanics Symposium, pp. 24-27, American Rock Mechanics Association, Chicago, IL, USA, June 2012.

[28] I. Finnie, G. A. Cooper, and J. Berlie, "Fracture propagation in rock by transient cooling," International Journal of Rock Mechanics and Mining Sciences \& Geomechanics Abstracts, vol. 16, no. 1, pp. 11-21, 1979.

[29] J. P. Holman, Heat Transfer, McGraw-Hill Inc., New York City, NY, USA, 1990.

[30] Z. W. Li, X. T. Feng, Y. J. Zhang, C. Zhang, T. F. Xu, and Y. S. Wang, "Experimental research on the convection heat transfer characteristics of distilled water in manmade smooth and rough rock fractures," Energy, vol. 133, pp. 206-218, 2017. 


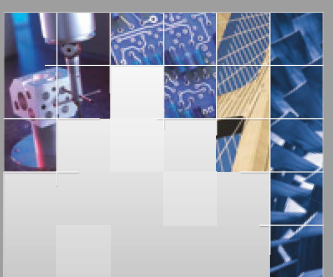

\section{Enfincering}
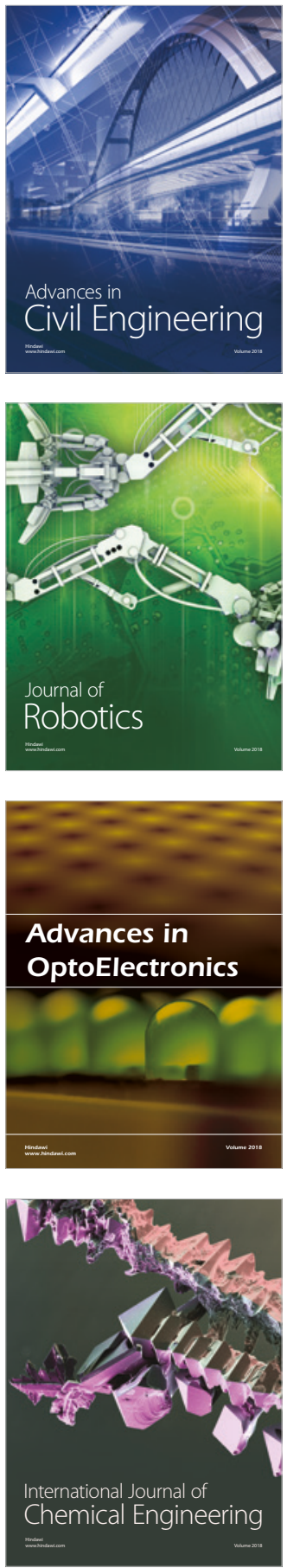

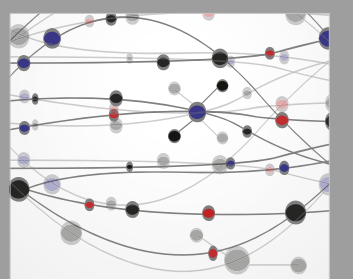

\section{Rotating \\ Machinery}

The Scientific World Journal

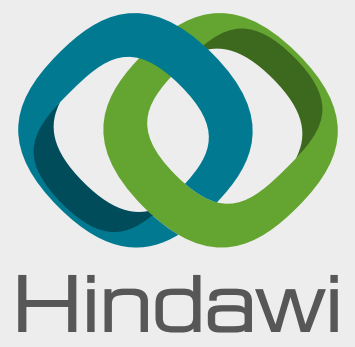

Submit your manuscripts at

www.hindawi.com
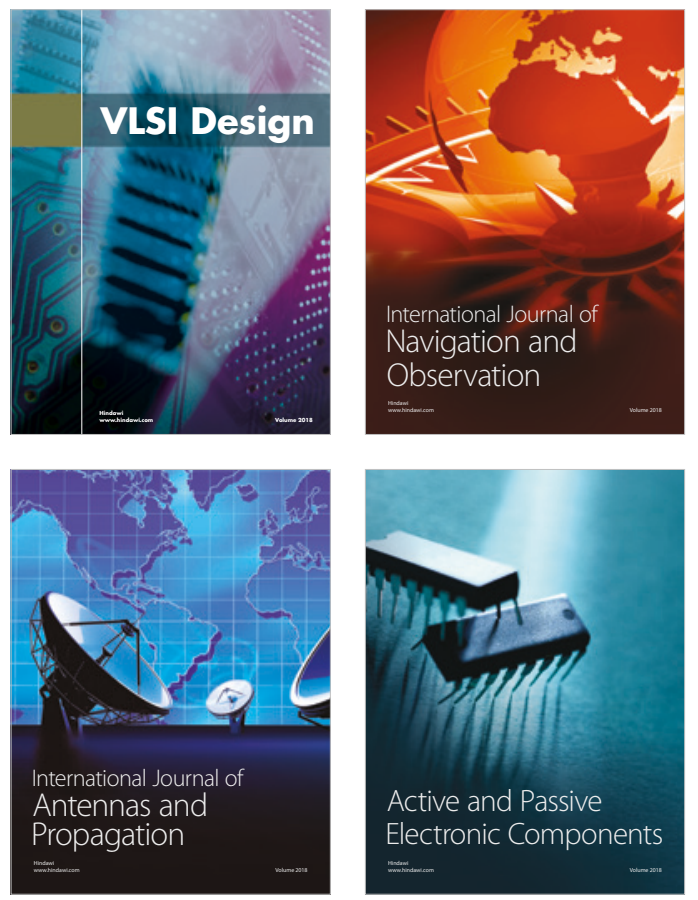
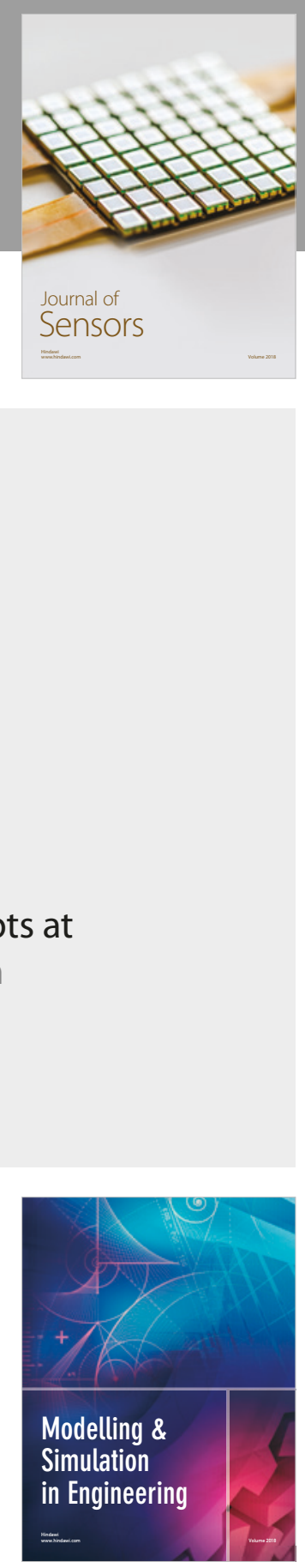

\section{Advances \\ Multimedia}
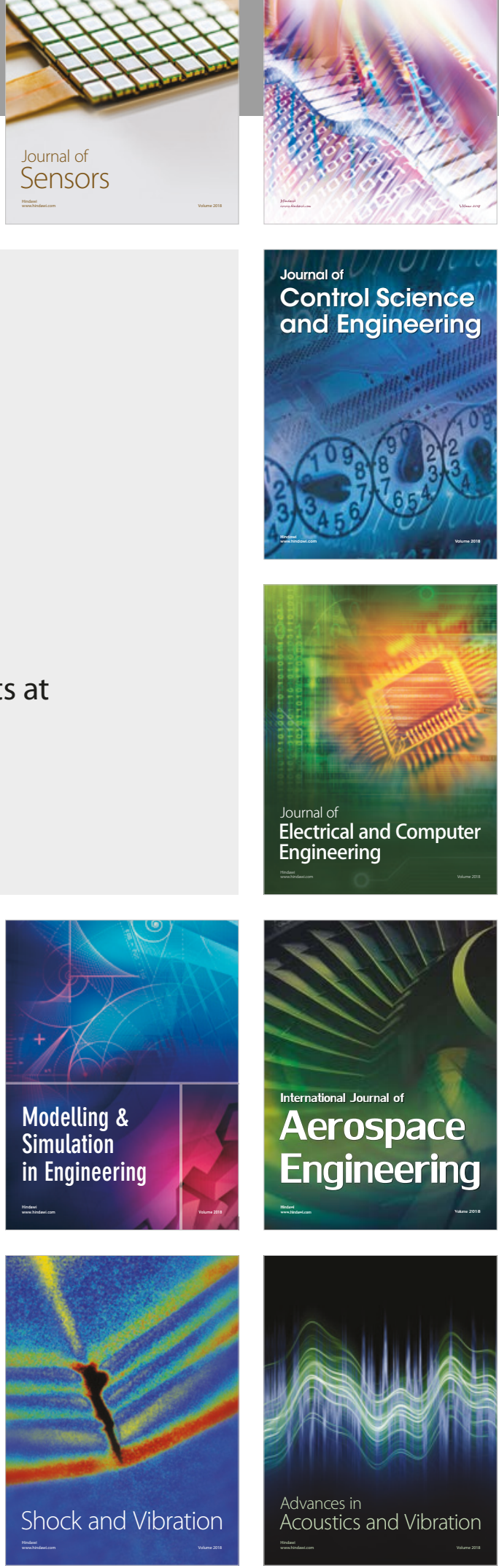